\title{
Grading Sphero-Cylinder Spectacle Similarity
}

This article was published in the following Dove Press journal:

Clinical Optometry

\author{
Robert W Arnold (DI) \\ Joshua S Beveridge' \\ Samuel J Martin' \\ Nathanael R Beveridge' \\ Elise J Metzger ${ }^{2}$ \\ Kyle A Smith $\mathbb{1 D}^{3}$ \\ 'The Alaska Blind Child Discovery, \\ Anchorage, AK 99508, USA; ${ }^{2}$ Grace \\ Christian School, Anchorage, AK, USA; \\ ${ }^{3}$ Kyle Smith, Accurate Vision, Anchorage, \\ AK, USA
}

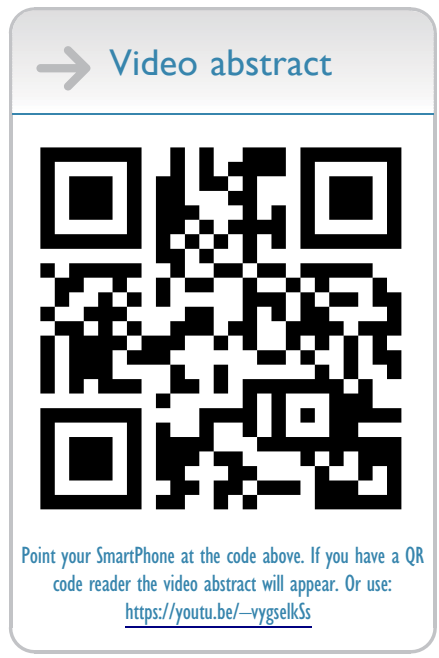

Correspondence: Robert W Arnold

The Alaska Blind Child Discovery, Alaska Children's EYE \& Strabismus, 3500

Latouche \#280, Anchorage, AK 99508,

USA

Tel + | $907561-1917$

Fax + I 907 563-5373

Email eyedoc@alaska.net
Background: Portable autorefractors can estimate refractive error in remote locations, but sphero-cylinder comparison and donated-spectacle dispensing are not yet simple.

Methods: Normal astigmats determined best corrected acuity, then degraded 1 logMAR (Grade A), $3 \log$ MAR (Grade B), and $6 \log$ MAR (Grade C) to determine limits of astigmatism axis and power at these levels. The cylindrical refraction was vector transformed with $\mathrm{J} 0$ on the abscissa and $\mathrm{J} 45$ on the ordinate.

Results: Ten subjects produced multiple refractions at the interfaces of Grades A, B, and $\mathrm{C}$ representing ovals on the $\mathrm{J} 0$ and $\mathrm{J} 45$ coordinates. When rotated, the vertical axis represented $45^{\circ}$ or $135^{\circ}$, the horizontal long axis was $1.6 \times$ the short axis. The size of the ovals positively correlated with cylinder power. Given a target refraction, the comparability of a candidate lens was demonstrated on our interactive database yielding a simple A, B, C, or worse grade for cylinder, spherical equivalent, and pupillary diameter.

Conclusion(s)/Relevance: Inputting a remote autorefraction, pupillary diameter and age as target and a donated spectacle as the candidate with a "B" grade similarity would be expected to attain 20/40 acuity (3 $\log$ MAR degrade) if best corrected visual acuity was 20/20. This practical Excel database could facilitate widespread remote lay dispensing of the cylinder as well as spherical spectacles. The grade similarity can also compare refracting tools such as photoscreeners and hand-held autorefractors.

Clinical Trials Registry: NCT04297969.

Keywords: donated recyled spectacles, remote dispensing, portable autorefraction, vision screen validation, forensic optometry

\section{Précis}

A system was developed to provide simple A, B, and C-grade comparison of two spectacle prescriptions based on the degree of visual acuity blur.

\section{Introduction}

There are times when it is important to compare two spectacle prescriptions. One that directly relates to our Alaska Blind Child Discovery project is validation, when the performance of refracting tools is compared to a gold-standard, actual refraction. ${ }^{1,2}$ Another reason relates to the remote dispensing of donated used spectacles. $^{3}$ A third reason for the simplified method of spectacle comparison is testimony related to when one pair of spectacles is found at a crime scene and matched to a different pair now worn by a suspect. ${ }^{4}$

For example, an experienced eye doctor gets an urgent call from a patient with significant myopic astigmatism that their recent glasses fell overboard. All the patient can find is a 10 -year-old pair with different sphere, cylinder, and axis. The 
doctor considers the patient's age and ability to accommodate, and reviews the two spectacle refractions noting moderate differences in spherical equivalent and astigmatism. With judgement acquired from examination of thousands of patients, advice is given,

With the old spectacles, you probably will see clear enough to retain your driver's license (20/40), but you will need to get an updated refraction to qualify for the target shooting team.

Would it be possible to derive a simple way to report this clinician's judgment; the similarity of two spectacles by their ability to produce a clear image?

Modern portable screening devices estimate actual refraction in adults and children. ${ }^{5}$ There are limitations as to how to report the precision of such estimates over a wide range of patients. Guo and Atchison ${ }^{6}$ described blur limits of astigmatism. Methods to compare spectacle prescriptions are not simple. ${ }^{7}$ There are technical methods to compare two spectacle refractions; Bland Altman plot analysis of vector transformed astigmatism ${ }^{8}$ is a valid, but complicated method for spectacle comparison. ${ }^{9}$ Time spent viewing through different fixed lenses in cages by nonhuman primates is a low tech method to compare objective and subjective refractions. ${ }^{10}$

Donated spectacles are made available for lay people to distribute to needy people in remote areas. ${ }^{11}$ The volunteers who staff the vision clinics usually lack extensive eye exam and optical knowledge. Lay screeners can transport and utilize recently available, practical portable devices that are capable of estimating spectacle refraction. If a wide variety of labeled, donated spectacles were available, a portable method to assist lay screeners in best distribution methods is currently lacking. In part due to these challenges, in a large review by Pearce, ${ }^{7}$ the current practice of dispensing donated spectacles was called into question.

Industry standard match. The Vision Council of America publishes the ANSI standards of the range of precision in sphere, cylinder, and axis required for custom manufactured dispensed spectacles. ${ }^{12}$

We undertook this study as an integral aspect of vision screening technology validation utilizing complex mathematical transformations designed to offer a simplified method for reporting the comparison of two spectacle refractions on the basis of the ability to resolve blur.

\section{Methods}

This comparative study of refractions obtainable by modern photorefractive vision screeners by the Alaska Blind
Child Discovery project was approved by the Providence Hospital Institutional Review Board. It complies with the Declarations of Helsinki and the Health Insurance Portability and Accountability Act. Written informed consent and assent were obtained. Co-authors participated as subjects.

The following paragraphs explain the complex vector mathematical transformation developed to generate in a simplified GRADE comparison of two spectacle refractions composed of the sphere, the cylinder, and the axis. First a range of spectacle cylinder powers and axes are clinically determined that allow healthy astigmatic subjects to see acuity optotypes uniformly blurred. Second, the resultant spectacle values are vector transformed. Then the $\mathrm{J} 0$ and $\mathrm{J} 45$ vectors are plotted on an $\mathrm{x}-\mathrm{y}$ axis generating concentric oval shapes with perfect identically matched spectacles in the center of the oval. Fourth, a candidate spectacle cylinder is plotted to determine the grade of expected blur compared to the target refraction. Fifth, a transform of spherical equivalent is based on age, accommodation, and over-plus. Sixth, the pupillary distance difference is graded based on spherical equivalent.

Clinically defining grade levels of spectacle similarity: In a typical clinical eye examination lane with a modern, M\&S (M\&S Technologies, Niles, Illinois) high resolution Visual Acuity chart calibrated for proper distance, and adjusted for logMAR (logarithm of minimum angle of resolution) Acuity increments, subjects were examined. As has been done validating other objective vision screeners in the past, ${ }^{13}$ for subjects with minimal astigmatism, toric contact lenses were used to briefly induce known quantities of cylinder.

The best optical refraction accounting for accommodation and with object and subjective refinement was obtained and recorded. Cycloplegia was used only to confirm whether residual accommodation had been adequately compensated. The ideal manifest target refraction for each (right and/or left) eye has sphere, cylinder, and axis defined as $\mathrm{SPH}_{\text {target }}$, $\mathrm{CYL}_{\text {target}}$, and $\mathrm{AXIS}_{\text {target }}$. Variables are listed in Table 1.

Using the ideal refraction, best corrected visual acuity (HOTV) was obtained with at least three of four optotypes correct. That best level acuity corresponded to the "target" best refraction.

We then sought which limits of refractive difference from target refraction specific levels of visual acuity could still be resolved. Adjustments in refraction maintained the sample spherical equivalent so as to avoid over-minus and the opportunity for the subject to improve acuity merely 
Table I Variables to Derive Spectacle Comparison GRADE Match

\begin{tabular}{|c|c|c|}
\hline Variable & Description & Formula \\
\hline $\mathrm{SPH}_{\text {target }}$ & Sphere component of gold-standard, target refraction & \\
\hline$C Y L_{\text {target }}$ & Cylinder component of target refraction & \\
\hline AXIS & Cylinder axis of target refraction & \\
\hline $\mathrm{SPH}_{\text {candidate }}$ & Sphere component of comparison spectacle & \\
\hline $\mathrm{CYL}_{\text {candidate }}$ & Cylinder of comparison spectacle & \\
\hline $\mathrm{AXIS}_{\text {candidate }}$ & Axis of the cylinder of comparison spectacle & \\
\hline $\begin{array}{l}\text { AXIS- } \\
A D J_{\text {candidate }}\end{array}$ & $\begin{array}{l}\text { Axis of candidate refraction rotated the same amount as target would be shifted to } \\
45^{\circ}\end{array}$ & Axis candidate $-\left(45^{\circ}\right.$-axis arget $\left._{\text {tar }}\right)$ \\
\hline$M_{\text {target }}$ & Spherical equivalent & $\mathrm{M}=\mathrm{SPH}_{\text {target }}+\mathrm{CYL} \mathrm{L}_{\text {target }} / 2$ \\
\hline$(00, j 45)$ & Plot of astigmatism vector components & \\
\hline j0-45 $5_{\text {target }}$ & Vector transform of target rotated horizontally with axis at $45^{\circ}$ & $\mathrm{J} 0=-(\mathrm{cy} / 2) \times \cos \left(2 * 45^{\circ}\right)$ \\
\hline J45-45 target & Vector transformed oblique component rotated to horizontal with axis at $45^{\circ}$ & $J 45=-($ cy $\mid / 2) \times \sin \left(2 * 45^{\circ}\right)$ \\
\hline$M_{\text {candidate }}$ & & $=\mathrm{SPH}+\mathrm{CYL} / 2$ \\
\hline J0-ADJ $J_{\text {candidate }}$ & & $\mathrm{J} 0=-(\mathrm{cy} \mid / 2) \times \cos (2 *$ axis-adj $)$ \\
\hline J45-ADJ $J_{\text {candidate }}$ & & $\mathrm{J} 45=-(\mathrm{cy} / / 2) \times \sin (2 *$ axis-adj $)$ \\
\hline “a” & Long oval axis & $\mathrm{a}=\operatorname{SQRT}\left(\left(0.39 *(x-h)^{\wedge} 2+(y-k)^{\wedge} 2\right) / 0.39\right)$ \\
\hline "b" & Short oval axis & $\mathrm{b}=$ short $\mathrm{axis}=0.63^{*} \mathrm{a}$ \\
\hline$A_{\text {quadratic }}$ & $0=A^{*}(\text { Grade })^{\wedge} 2+B *($ Grade $)+C$ & $A=-0.048\left(\left.C y\right|_{\text {target }}\right)$ \\
\hline$B_{\text {quadratic }}$ & Grade $=\left(-B+\operatorname{sqrt}\left(B^{\wedge} 2-4^{*} A * C\right)\right) / 2 * A$ & $B=0.29 *\left(\left.C y\right|_{\text {target }}\right)+0.319$ \\
\hline $\mathrm{C}_{\text {quadratic }}$ & Component of equation & $C=-($ diameter $)=-2 * a$ \\
\hline Accom & Degree of accommodation required between refractions & Accom $=M_{\text {candidate }}-M_{\text {target }}$ \\
\hline Accom $_{\text {excess }}$ & Excess accommodation & \\
\hline PD & Pupillary distance & GradePD $=\Delta P D /\left(4.165 * e^{\wedge}-\left(-0.1 * M_{\text {target }}\right)\right.$ \\
\hline Grade $_{P D}$ & Degree of pupillary distance match & $\Delta P D=\left|P D_{\text {target }}-P D_{\text {candidate }}\right|$ \\
\hline A-Grade & Clinical degradation from best corrected acuity to I logMAR worse & \\
\hline B-Grade & Degradation from best corrected to 3 logMAR worse visual acuity & \\
\hline C-Grade & Degradation from best corrected to 6 logMAR worse & \\
\hline M & Spherical equivalent & $=\mathrm{SPH}+\mathrm{CYL} / 2$ \\
\hline j0 & Vector transformed Jackson Cross horizontal & $\mathrm{J} 0=-(\mathrm{cyl} / 2) \times \cos (2 * \mathrm{a} x \mathrm{is})$ \\
\hline j45 & Vector transformed Jackson Cross oblique & $J 45=-(c y \mid / 2) \times \sin (2 * a x i s)$ \\
\hline$(h, k)$ & $x$ and $y$ coordinates of center of an oval & \\
\hline$(x, y)$ & $x$ and $y$-coordinate of a point on the circumference of an oval & \\
\hline Grade $_{a}$ & Quality of Accommodation match & $\mathrm{GRADE}_{\mathrm{a}}=\mathrm{accom} /(0.02 *$ age -1.5$)$ \\
\hline Slope $_{a}$ & & Slope $_{a}=0.02\left(\right.$ Grade $\left._{a}\right)$ \\
\hline Intercept $t_{a}$ & & Intercept $t_{\mathrm{a}}=-1.5\left(\right.$ Grade $\left._{\mathrm{a}}\right)$ \\
\hline Age & Age in years & \\
\hline OverPlus & & Overplus $=0.5 *$ Grade \\
\hline Accom $_{\text {expect }}$ & & $A_{c c o m}{ }_{\text {exp }}=5.25 * e^{\wedge}(-0.05 * A g e)$ \\
\hline
\end{tabular}

through accommodation and associated miosis. The degraded visual acuity was defined as:

A-Grade: 1 logMAR line worse (larger optotype) than target.

B-Grade: $3 \log$ MAR lines worse than target, and 2 lines less than A-level.

C-Grade: 6 logMAR lines worse than target, and 3 $\log$ MAR lines less than B-level.

A patient with best corrected visual acuity of $20 / 20$ would have an A-Grade of 20/25, a B-Grade of 20/40, and a C-Grade of 20/80.

\section{Defining Refractions at Grade-Level Degradations of Visual Acuity}

The target level refraction is placed in the phoropter for the favorite, or preferred eye. After assuring easy ability to resolve the target acuity level, then the A-level limit acuity $1 \log$ MAR line degraded is projected on the acuity chart.

Then the target refraction sphere, cylinder, and axis is confirmed and the axis rotated in a clockwise direction until the patient can no longer resolve the A-level limit visual acuity (using an optotype with both horizontal and vertical components, ie, "H" or "T"). With $\mathrm{SPH}_{\text {target }}$ and 
$\mathrm{CYL}_{\text {target }}$ still in the phoropter, the new clockwise rotated A-level axis is recorded. Then the phoropter is returned to target refraction and the axis is rotated counterclockwise until the A-Grade optotype is no longer legible.

Next, the phoropter would be brought back to target refraction, and additional cylinder (plus) power dialed in. The cylinder would be increased by 0.25 diopters with original target axis in the phoropter and original target sphere. The patient would see if they can see the A-Grade, $1 \log$ MAR degraded optotype. If so, the axis would be rotated clockwise until the optotype was no longer legible, and recorded. Then the axis would be rotated counterclockwise beyond the target axis to the farthest clockwise the optotype can still be resolved.

The same process would then be done starting back at target refraction, and decreasing cylinder power to 0.25 D less than target with sphere unchanged. If the A-Grade optotype is visible, then rotate axis clockwise, and then counterclockwise to determine the axis limits of the A-Grade optotype with small cylinder power adjust.

Next, starting back at target refraction, add 0.50 diopters to the cylinder power but decrease the sphere by 0.25 $\mathrm{D}$ to maintain constant spherical equivalent. If the A-Grade optotype is legible, rotate axis clockwise, and also counterclockwise to determine axis limits for the A-Grade optotype acuity degrade.

The method is to obtain combinations with the same spherical equivalent with varied cylinder power and axis that define the limits of legibility of optotypes for the A-Grade.

Next, repeat the process for the B-Grade degrade optotype of adjusting astigmatism axis clockwise and counterclockwise away from target refraction starting from initial target cylinder power, and then also modifying cylinder power up and down, maintaining spherical equivalent.

Finally, repeat the cycle for C-Grade optotype degrades.

\section{Derivation of Grading Function}

Relationships between various target refractions, subject age, and the limits of Grade-A, Grade-B, and Grade-C visual acuity were analyzed using regressions and mathematical modeling.

Sample Size: For this example with low variance a sample size greater than $n=8$ needed to clearly define data shape. ${ }^{14}$

\section{Results}

The limits of the cylinder and axis to achieve A-Grade, B-Grade, and C-Grade defocus were obtained from eight individuals with normal best-corrected visual acuity despite substantial astigmatism. Cylinders ranged from 0.5-5.25 diopters with an average of 3 diopters. Three were with-the-rule, one against-the-rule, and four oblique. Spherical equivalent ranged from from -3.12 to +4.25 diopters. Subjects ranged in age from 13-62 years. All subjects resolved $20 / 20$ or better with ideal (target) refraction.

There was a strong correlation between the cylinder and the number of degrees the original target cylinder could be rotated to determine A-Grade, B-Grade, and C-Grade blur. For A-Grade, axis rotation $=-2.3$ (cylinder) +24 degrees $\left(\mathrm{R}^{2}=0.32\right)$. For $\mathrm{B}-\mathrm{Grade}$, axis rotation $=-3.4$ (cylinder) $+34\left(\mathrm{R}^{2}=0.42\right)$. For $\mathrm{C}$-Grade blur, axis rotation= -4.9 (cylinder) $+47\left(\mathrm{R}^{2}=0.55\right)$.

To assist mathematical regressions, the grade of blur was assigned a numerical value - not exactly like the grade point average from schools, where an $\mathrm{A}$ is equivalent to 4.0. Instead, the target condition was assigned 0 (zero). A-Grade $1 \log$ MAR blur was assigned 1.0, B-Grade $3 \operatorname{logMAR}$ blur assigned 2.0, and C-Grade 6 logMAR blur assigned 3.0.

\section{Astigmatism}

Initially each refraction sphere, cylinder, and axis was converted to spherical equivalent (M) and $\mathrm{J} 0$ and $\mathrm{J} 45$ vector transformations. ${ }^{8}$

Spherical equivalent $\mathrm{M}=$ sphere $+($ cylinder $/ 2)$

$\mathrm{J} 0=-(\mathrm{cyl} / 2) \mathrm{x} \cos (2 \mathrm{xaxis})$

$\mathrm{J} 45=-(\mathrm{cyl} / 2) \mathrm{x} \sin (2 \mathrm{xaxis})$

A novel plotting method was then devised; a plot of the vector transformed astigmatism with $\mathrm{J} 0$ having the $\mathrm{x}$-value and J45 having the $y$-value. The resultant plot has units measuring $1 / 2$ cylinder power and the transformed axes have $90^{\circ}$ directed east, $45^{\circ}$ directed north, $135^{\circ}$ directed south, and $0^{\circ}=180^{\circ}$ directed west.

Clinical examples with grade level refractive limits vector transformed are plotted resulting in a central point with the target refraction and the A-level acuity degrade set of refractions, the B-level degrade, and the C-level degrade producing enlarging, concentric ovals each centered on the representative target axis (Figure 1). The long axis of each oval is perpendicular to the ray subtending the target axis, and the short axis parallel to the target axis 

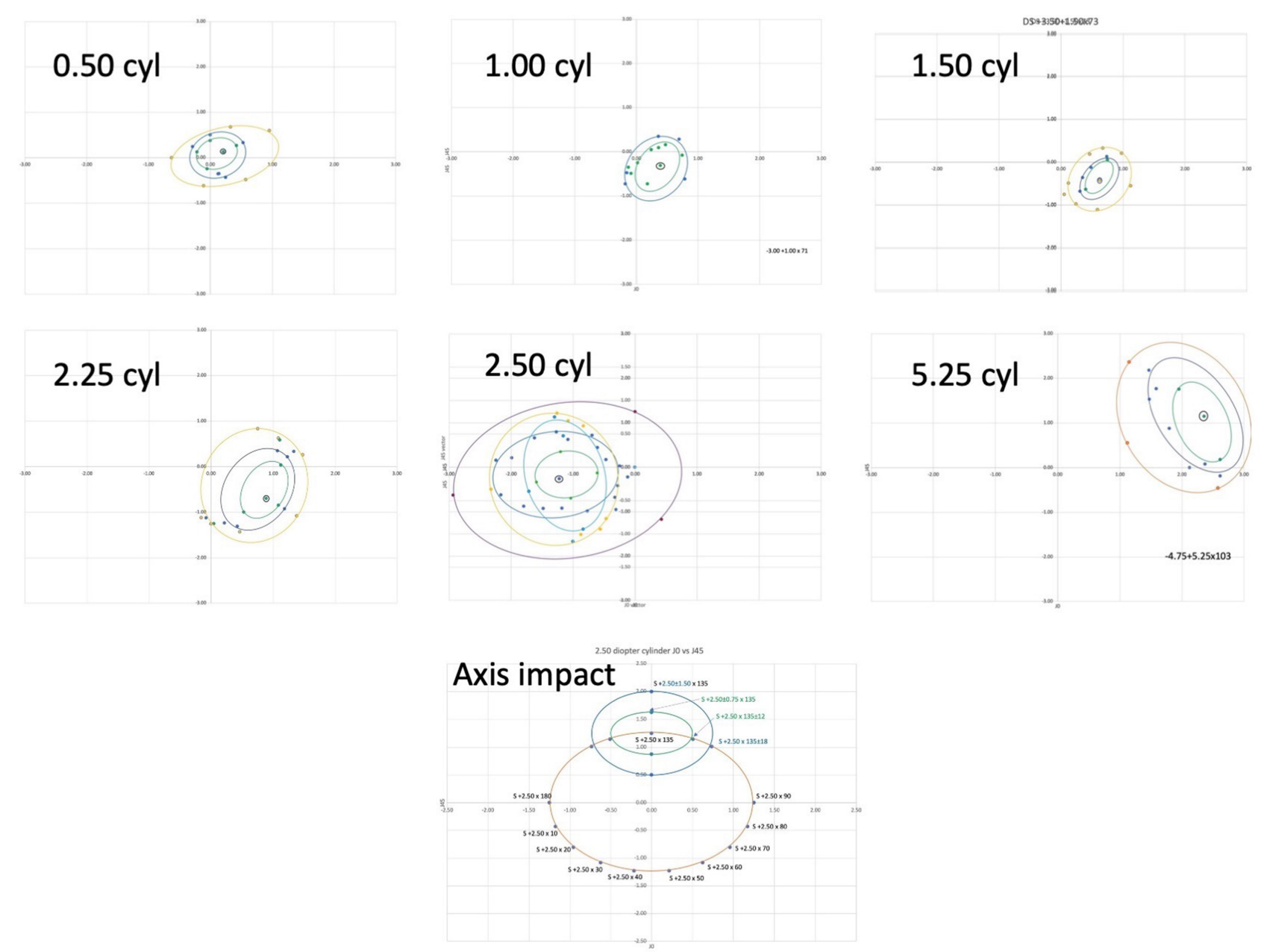

Figure I 10 vs $J 45$ vector transformed astigmatism A, B, and C matched degraded visual acuity. Example subjects with cyl 0.5, I.0, I.5, 2.25 contact lens, 2.50 , and 5.25 D. The lower graph shows an example spectacle with cylinder axis converted to $45^{\circ}$ such that orientation of the concentric A-Grade, B-Grade, and C-Grade ovals have the long axis "a" oriented horizontally.

subtended ray. We found that the long axis averages 1.6-times as long as the short axis.

The formula for each point $(x, y)$ on the circumference of an oval with center $(\mathrm{h}, \mathrm{k})$, and long axis $\mathrm{a}$, and short axis $\mathrm{b}$ is:

$(h-x)^{\wedge} 2 / a^{\wedge} 2+(k-y)^{\wedge} 2 / b^{\wedge} 2=1$ for a horizontally oriented oval.

Therefore, the Target Astigmatism is rotated to $45^{\circ}$, for a rotation of $\left(45^{\circ}\right.$-Axis target $)$ degrees. This deliberate rotation of the target refraction allows for the oval circumference formula since the oval is now oriented horizontally on the north end of the $\mathrm{J}_{45 \text {-target, }} \mathrm{J} 5_{45 \text {-target }}$ Cartesian coordinate (Figure 2). Conversion to J0 and J45 Jackson Cross coordinates resolves issues of axis disparity near $180^{\circ}$ because the conversion allows actual spectacle axes $0^{\circ}$ to $180^{\circ}$ to extend a full circle. The conversion works well for plus or minus cylinder notation.

$\mathrm{a}=$ long axis

$\mathrm{b}=$ short axis $=0.63 * \mathrm{a}$

$$
(h-x)^{2} / a^{2}+(k-y)^{2} / b^{2}=1
$$

The long axis for each subject and the A-Grade, B-Grade, and C-Grade ovals is then measured and compared to Target cylinder power (Figure 3).

For A-Grade, $2 * \mathrm{a}=0.25\left(\mathrm{Cyl}_{\text {target }}\right)+0.46$

For B-Grade, $2 * \mathrm{a}=0.38\left(\mathrm{Cyl}_{\text {target }}\right)+0.64$

For C-Grade, $2 * \mathrm{a}=0.44\left(\mathrm{Cyl}_{\text {target }}\right)+0.91$

Analyzing each equation, the given number value for grade:

Slope-oval $=0.095 *$ Grade +0.167

Intercept-oval $=0.23 *$ Grade +0.22

Solving for Grade requires a quadratic equation

$$
0=A^{*}(\text { Grade })^{2}+B^{*}(\text { Grade })+C
$$

$$
\begin{gathered}
\mathrm{A}=-0.048\left(\mathrm{Cyl}_{\text {target }}\right) \\
\mathrm{B}=0.29 *\left(\mathrm{Cyl} l_{\text {target }}\right)+0.319 \\
\mathrm{C}=-(\text { diameter })=-2 * \mathrm{a}
\end{gathered}
$$




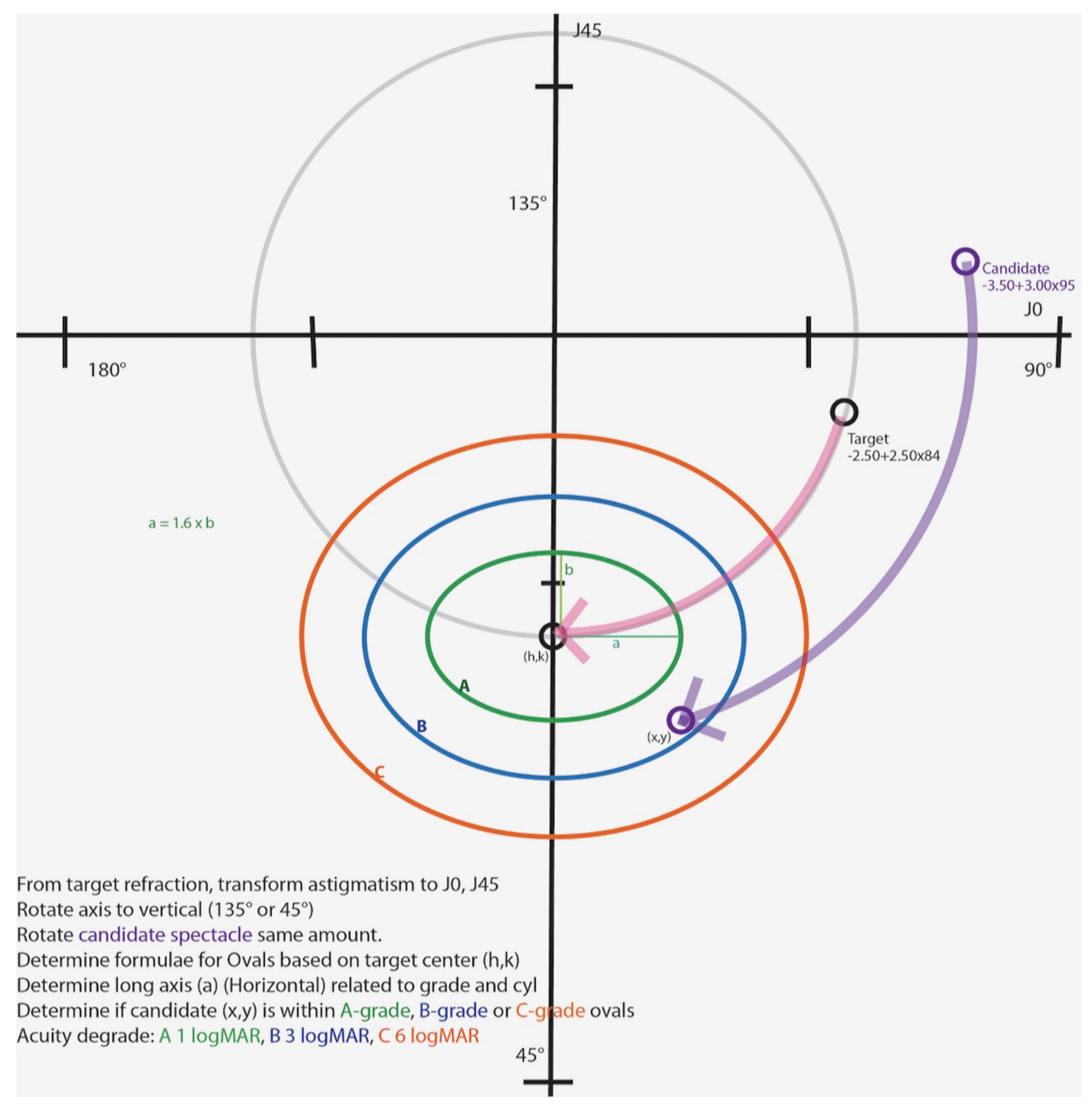

Figure $2 \mathrm{~J} 0$ vs $\mathrm{J} 45$ ovals and grades. Method to rotate target to $45^{\circ}$ so horizontal and then generate oval boundaries (green A, blue B, and orange C to determine whether a candidate refraction, also rotated, is within a given visual acuity-derived Grade level comparison.

Diameter $=2 *$ long axis $=2 * a$

$$
\text { Grade }=\left(-B+\operatorname{sqrt}\left(B^{2}-4 * A * C\right)\right) / 2 * A
$$

This is the equation to generate the comparison grade for cylinder.

\section{Spherical Equivalent}

Accommodation is related to age (Figure 4). The degree $\left(\right.$ Grade $\left._{\mathrm{a}}\right)$ of "over-minus" a person can tolerate in their spectacles is a function of age (Figure 4). Younger patients can generate, and tolerate more accommodation than older patients. However, excess accommodative stimulus in younger patients could produce esotropia and amblyopia. A small amount of excess hyperopic correction will move near point to 2 meters, but probably still allow distant resolution of 1-3 logMAR below best corrected.

Target spherical equivalent: best correction sphere plus $1 / 2$ cylinder power $=\mathrm{M}_{\text {target }}$.
Figure 3 shows that Spherical Equivalent Accommodation $=\mathrm{M}_{\mathrm{a}}=$ slope $_{\mathrm{a}}$ (age $)+$ intercept $_{\mathrm{a}}$.

Slope $_{\mathrm{a}}=0.02 *\left(\right.$ Grade $\left._{\mathrm{a}}\right)$

Intercept $_{\mathrm{a}}=-1.5 *\left(\right.$ Grade $\left._{\mathrm{a}}\right)$

Solving for grade can yield a result from 0 (perfect target match) to 1 (A-match yields acuity within one $\log$ MAR line) to 2 (B-match yields acuity within 3 $\log$ MAR lines), and then 3 (C-match yields acuity degraded to $6 \log$ MAR lines).

Grade $_{\mathrm{a}}$ can also be solved given the patient's age to determine the degree which the spherical equivalent of candidate spectacle compares to the target spectacle, whether there is too much "over minus" for the patient's age.

ExpectedAccommodation $=$ Accomexp $=5.25 * e^{(-0.05 * \text { Age })}$

Overplus $=0.5 *$ Grade $_{\mathrm{a}}$

$$
\text { Accom }=\mathrm{M}_{\text {candidate }}-\mathrm{M}_{\text {target }}
$$




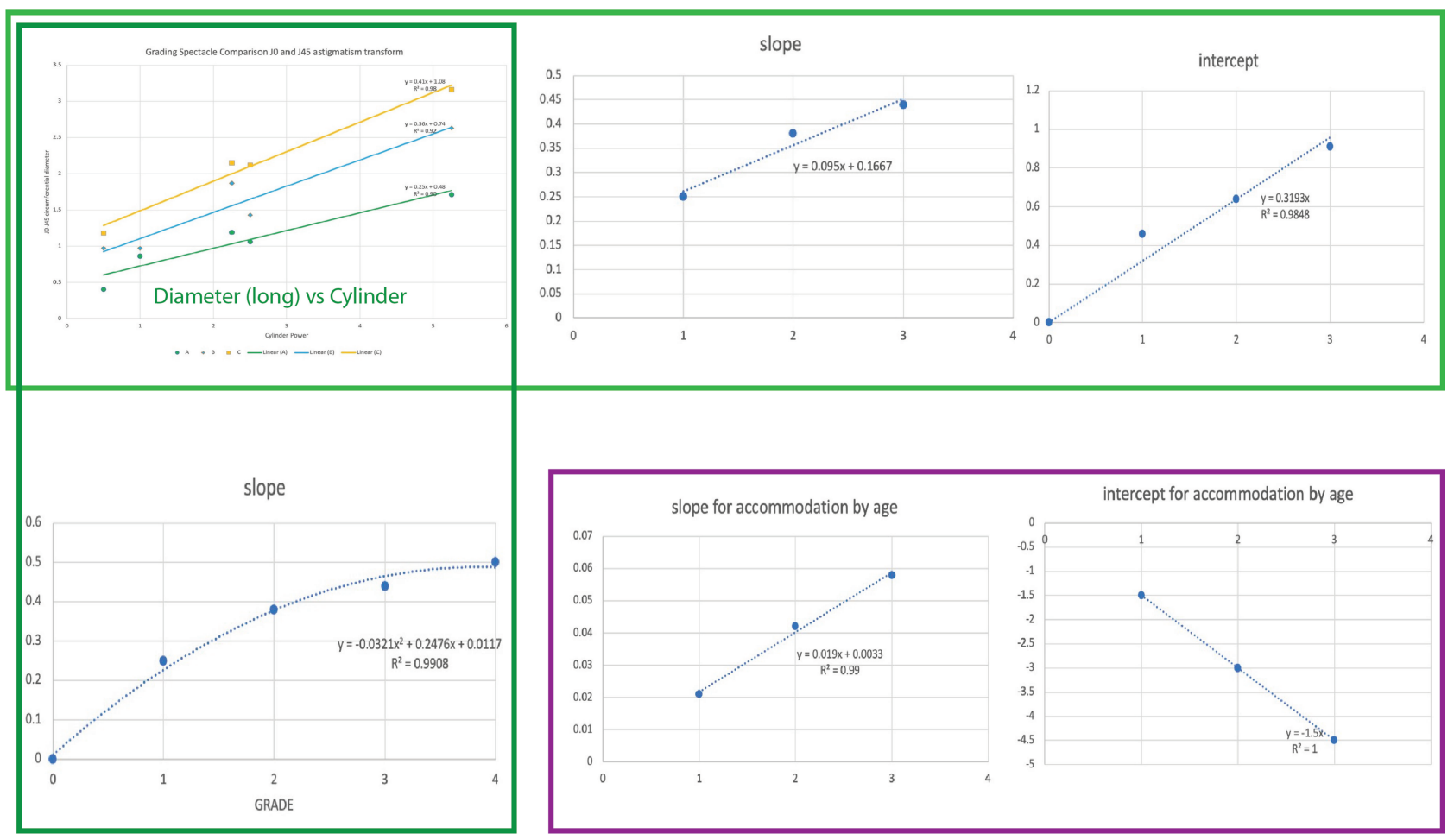

Figure 3 Linear relationship between A-match (green), B-match (blue), and C-match (orange) visual acuity degrades I logMAR, 3 logMAR, and 6 logMAR. Diameter of degrade limits versus cylinder power. The slope and intercept for derived long axis length versus cylinder (upper left graph) is related to Grade (upper right graphs). The slope and intercept (lower left) of over-minus spherical equivalent Grade is related to age (lower right).

\section{Grade $_{\mathrm{a}}=$ Accom $/(0.02 *$ Age -1.5$)$}

This is the GRADE relative to spherical equivalent and accommodation related to age.

\section{Pupillary Distance (PD)}

The distance between optical centers of each lens should match the eyes - even more so when the refractive error (spherical equivalent) increases.

An A-match for spectacles spherical equivalent 1 diopter could be off by $4-5 \mathrm{~mm}$, but spectacles with spherical equivalent 6 diopters should be within $2 \mathrm{~mm}$. A C-match for 1 diopter might be off by $8 \mathrm{~mm}$, but for 6 diopters only off by $4 \mathrm{~mm}$.

$$
\begin{aligned}
& \Delta \mathrm{PD}=\left|\mathrm{PD}_{\text {target }}-\mathrm{Pd}_{\text {candidate }}\right| \\
& \text { GradePD }=\Delta P D /\left(4.165 * e^{-}(-0.1 * \text { Mtarget })\right.
\end{aligned}
$$

\section{Download}

Functioning Excel (Microsoft) and Numbers (Apple) databases that can deliver grade comparisons for astigmatism, spherical equivalence, and pupillary distance are available for free download: http://www.abcd-vision.org/visionscreening/Spectacle $\% 20$ Comparison\%20Grade.html

\section{ANSI Example}

The outer limits of commercial spectacle manufacture for dispensing established by the American National Standards Institute (ANSI; z80.1 2015) were subjected to this new spectacle comparison grading using the Microsoft Excel interactive database. ANSI allows for some variance in astigmatism axis inversely proportional for the cylinder magnitude: from a target 0.50 diopter cylinder, a shift of 7 degrees axis yields Grade 0.22 (high A), for a 0.75 diopter cylinder, a shift of 5 degrees get Grade 0.21 and for a cylinder $1.50 \mathrm{D}$, a shift of axis 3 degrees yields our Grade 0.19. Combined sphero-cylinder target -0.50 $+2.00 \times 90$ manufactured just within ANSI $-0.63+2.13 \times 92$ scores our Grade 0.27 a high A. For more extreme lenses, the target $-8.50+3.50 \times 90$ the ANSI limit of -8.67 $+3.68 \times 92$ gets the astigmatism grade of 0.29 and a spherical equivalent grade age 40 of 0.16 , both high As.

\section{Crime Suspect Example}

Years ago, a district attorney brought us two pairs of spectacles asking two questions: 1) Could these both belong to the same person? and 2) How common or rare are these spectacles? We had not yet developed this comparative tool, but applied both spectacle prescriptions. From one [ID-altered] 


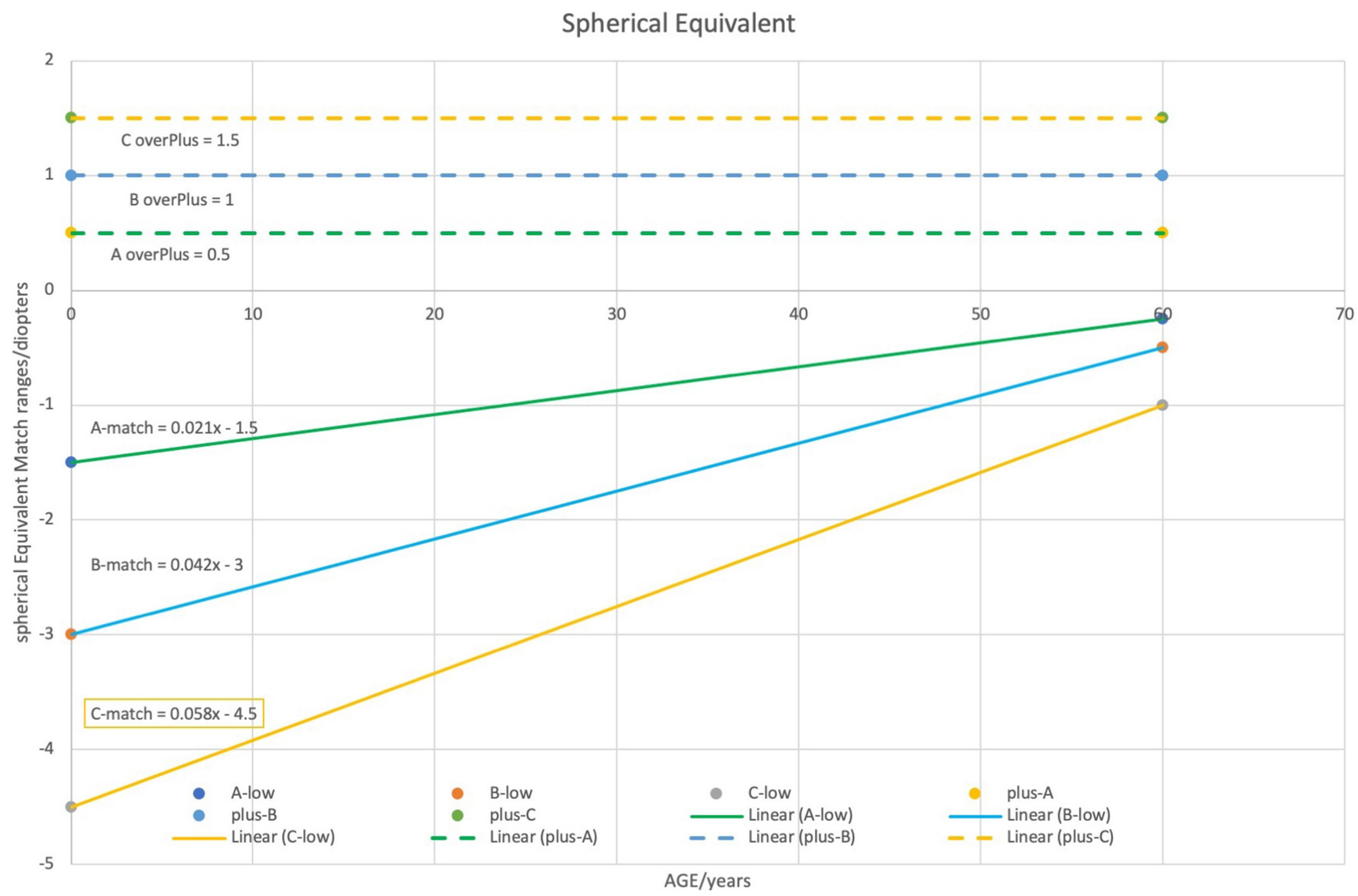

Figure 4 Spherical equivalent match related to age and accommodation. Over plus produces similar distance blur at all ages while over minus is better tolerated by young patients. A-match (green), B-match (blue), and C-match (orange) visual acuity degrades I logMAR, 3 logMAR, and 6 logMAR.

lens $-6.25+2.50 \times 76$ with PD 56, the compared lens -6.00 $+2.25 \times 80$ with PD 58 had the following Grade scores from our interactive database: cylinder $0.52(\mathrm{~A})$, spherical equivalent age 25 score 0.20 (A) and PD match 0.30 (A). This simplified scoring would have assisted in informing the jury.

\section{Conclusion}

A simplified method to compare spectacle refractions has been presented giving a familiar " $A$ ", "B", and "C" grade to astigmatism as well as spherical equivalent related to age and pupillary distance. The Alaska Blind Child Discovery is already investigating how this method can compare photoscreening devices with gold-standard refractions and evaluate our scores compared to Bland Altman analysis of vector transformed refractions.

Organizations like the Lions Clubs collect donated spectacles and then carefully clean and refurbish them, cataloguing the refractive error of each. The recycling centers recognize that these donated spectacles will likely be dispensed by non-eye professionals in remote communities. Therefore, the Lions carefully cull refractions that might lead to headache or asthenopia. As a result, potentially disturbing levels of astigmatism, anisometropia, reading add, prism, and altered interpupillary distance are excluded. Without a simple means of comparing astigmatism lenses to portable autorefractors, most spectacles with cylinders have so far not been available for remote dispensing. A remote patient with anisometropia will often enjoy a bilaterally symmetric spectacle even if it provides a moderately close match to even just one of their eyes.

Shane et $\mathrm{al}^{15}$ showed that used spectacles were slightly better than ready-made spectacles for improving uncorrected visual acuity in adults. Wang et $\mathrm{al}^{16}$ found adjustable spectacles only a bit inferior to standard spectacles for teenage school children. Global Revision has catalogued thousands of donated spectacles for use in Mexico using a special matching program (https://www.youtube.com/watch?v= egwtCnRKmw8andfeature=email; http://www.globalrevi sion.org). This program requires a vast number of donated spectacles, careful autorefraction, and a sophisticated spectacle comparison method familiar only to optical professionals. Unfortunately many remote vision clinics are not staffed by volunteers with optical knowledge. Our new method could be combined with a catalogued collection of refurbished, donated 
spectacles. As is currently the practice, spectacles with prism, high anisometropia, and strong bifocals would not be included in an assortment intended for remote dispensing.

The strengths of this study are directly obtained refractive data with a high resolution calibrated visual acuity chart and careful application of conventional vector transformation of the cylinder. The application of J0 versus J45 on a new twodimensional graph is novel. Weaknesses of the study include the moderately small sample size over certain ranges of astigmatism power and the need for separate components of sphere and cylinder comparison grade instead of having one uniform grading method for sphere plus cylinder. Also, two examples of clinical application are provided, but further study of spectacle refraction grading with this method compared to Bland Altman plot are forthcoming.

This simplified method could be adapted to portable computers and smart phones, and could aid delivery of inexpensive, donated spectacles to needy persons worldwide. A simple comparison would also aid in validation of refraction tools and even in forensic optometry.

\section{Data Access}

http://www.abcd-vision.org/vision-screening/Spectacle $\%$ $20 \mathrm{Match} \% 20 \mathrm{Grade} / \mathrm{de}-\mathrm{ID} \% 20 \mathrm{Spec} \% 20 \mathrm{Match} \%$ 20GRADE.pdf

\section{Disclosure}

Drs. Arnold and Smith are board members of PDI Check that makes a vision screening game for the autostereoscopic Nintendo 3DS console with a PDI Check pending patent. Dr. Arnold is also President and a board member of Glacier Medical Software which markets cloud-based NICU monitoring software ROP Check. Dr. Arnold is a non-paid advisor for Adaptica, plusoptiX and Go Check Kids. Dr. Arnold is coordinator of the Alaska Blind Child Discovery which has received discounted vision screen technology from several vendors. Dr. Arnold is also an investigator and protocol developer for the NIH-supported Pediatric Eye Disease Investigator Group (PEDIG). The authors report no other conflicts of interest in this work.

\section{References}

1. Levitt AH, Martin SJ, Arnold RW. Performance of glow-fixation GCK and 2WIN photoscreeners and Retinomax to uncover hyperopia. Clin Ophthalmol. 2020;14:2237-2244. doi:10.2147/ OPTH.S256991

2. Kirk S, Armitage MD, Dunn S, Arnold RW. Calibration and validation of the 2 WIN photoscreener compared to the plusoptiX S12 and the SPOT. J Pediatr Ophthalmol Strabismus. 2014;51(5):1-4.

3. Arnold RW, Arnold AW. Refractive error in Myanmar. Ophthalmology. 2008;115(9):1642-1643. doi:10.1016/j.ophtha.20 08.05.018

4. Collins RS, Berg GE. Forensic application of optical correction. Optometry. 2008;79(4):203-207.

5. Arnold SL, Arnold AW, Sprano JH, Arnold RW. Performance of the 2 WIN photoscreener with "CR" strabismus estimation in high risk patients. Am J Ophthalmol. 2019;207:195-203. doi:10.1016/j.ajo.20 19.04.016

6. Guo H, Atchison DA. Subjective blur limits for cylinder. Optom Vis Sci. 2010;87(8):E549-559. doi:10.1097/OPX.0b013e3181e61b8f

7. Pearce MG. Clinical outcomes following the dispensing of ready-made and recycled spectacles: a systematic literature review. Clin Exp Optom. 2014;97(3):225-233.

8. Miller JM. Clinical applications of power vectors. Optom Vis Sci. 2009;86(6):599-602. doi:10.1097/OPX.0b013e3181a6a211

9. Fu D, Ding X, Shang J, Yu Z, Zhou X. Accuracy of WASCA aberrometer refraction compared to manifest refraction and cycloplegic refraction in hyperopia measurement. TVST. 2020;9(11):5. doi:10.1167/tvst.9.11.5

10. Wesner MF, Young FA. Comparison of subjective lens preference to objective refractive error measurements in pigtail macaques. $\mathrm{Am}$ J Optom Physiol Opt. 1986;63(3):193-197. doi:10.1097/00006324198603000-00005

11. Ramke J, Du Toit R, Brian G. An assessment of recycled spectacles donated to a developing country. Clin Exp Ophthalmol. 2006;34 (7):671-676. doi:10.1111/j.1442-9071.2006.01306.x

12. Brown WL. Revisions to tolerances in cylinder axis and in progressive addition lens power in ANSI Z80.1-2005. Optometry. 2006;77 (7):343-349. doi:10.1016/j.optm.2006.04.108

13. Arnold RW, Davis B, Arnold LE, Rowe KS, Davis JM. Calibration and validation of nine objective vision screeners with contact lens-induced anisometropia. J Pediatr Ophthalmol Strabismus. 2013;50(3):184-190. doi:10.3928/01913913-20130402-02

14. Jenkins DG, Quintana-Ascencio PF, Han G. A solution to minimum sample size for regressions. PLoS One. 2020;15(2):e229345. doi:10.1371/journal.pone. 0229345

15. Shane TS, Shi W, Schiffman JC, Lee RK. Used glasses versus ready-made spectacles for the treatment of refractive error. Ophthalmic Surg Lasers Imaging. 2012;43(3):235-240. doi:10.39 28/15428877-20120223-02

16. Wang CY, Zhang G, Tang B, et al. A randomized noninferiority trial of wearing adjustable glasses versus standard and ready-made spectacles among Chinese schoolchildren: wearability and evaluation of adjustable refraction III. Ophthalmology. 2020;127(1):27-37. doi:10.1016/j.ophtha.2019.08.002 


\section{Publish your work in this journal}

Clinical Optometry is an international, peer-reviewed, open access journal publishing original research, basic science, clinical and epidemiological studies, reviews and evaluations on clinical optometry. All aspects of patient care are addressed within the journal as well as the practice of optometry including economic and business analyses. Basic and clinical research papers are published that cover

Submit your manuscript here: https://www.dovepress.com/clinical-optometry-journal all aspects of optics, refraction and its application to the theory and practice of optometry. The manuscript management system is completely online and includes a very quick and fair peer-review system, which is all easy to use. Visit http://www.dovepress.com/ testimonials.php to read real quotes from published authors. 